\title{
A collaborative investigation of health impact and water quality improvement in Oworobong, Ghana
}

\author{
D. A. Lardner ${ }^{1}$, S. Meyland ${ }^{2}$, M. K. Jung ${ }^{3} \&$ M. D. Passafaro ${ }^{1}$ \\ ${ }^{1}$ Center for Global Health, New York Institute of Technology, USA \\ ${ }^{2}$ Department of Engineering and Computing Science, \\ New York Institute of Technology, USA \\ ${ }^{3}$ Office of Research, College of Osteopathic Medicine, \\ New York Institute of Technology, USA
}

\begin{abstract}
Rural communities in the developing world rely on unsafe surface water which have significant contamination from runoff. This project involved a multidisciplinary international team approach to create a sustainable water supply to an isolated health clinic in a rural village in Ghana. Water testing was conducted over a one year period from the community's major water sources and compared to World Health Organization (WHO) and the European Commission guidelines. The engineering team completed a sanitary survey and designed a sustainable rainwater collection system that incorporates filtration and ozone treatment. The project also reviewed medical records of diarrheal disease and malaria cases in the community between wet and dry seasons. The results of statistical analysis showed a trend, though not significant, among the younger patients (ages 0-19) for increased prevalence of waterborne disease during the wet season $(19.7 \%)$ compared to the dry season $(16.0 \%)$ (p-value $<0.09)$. There was a significant difference in the prevalence of malaria depending on seasons when stratified by gender and age: an increased prevalence of malaria for older women in the dry season $(33.7 \%)$ compared to the wet season $(24.8 \%)$, (p-value $<0.01)$. This paper describes the project and interdisciplinary design.
\end{abstract}

Keywords: Kwahu-South, Ghana, waterborne disease, multidisciplinary collaboration, rainwater collection, ozone treatment. 


\section{Introduction}

It has been well established by international literature that overall mortality due to diarrhea is attributable to the lack of access to potable improved water sources [1-5]. Types of improved water sources include piped water into a dwelling/yard/plot, a public tap/standpipe, a tube well or borehole, a protected dug well, and protected spring or rainwater. Yet, the creation of these improved sources have been insurmountable in many parts of the developing world. Diarrhea remains the second leading cause of death worldwide among children under five years old reaching nearly 1.5 million each year. It kills more young children each year than AIDS, malaria, and measles combined [6].

This project was conducted in Ghana which ranks 130 out of 169 countries in health, education and living standards according to the Human Development Index (HDI) [7]. Ghana has received a higher HDI than other countries in subSaharan Africa. However, it continues to suffer from many of the same health problems including waterborne disease (those that are transmitted through ingestion of infectious agents) and water based disease (those that require intermediate aquatic hosts or water related insect vectors) like malaria which is endemic to the area [8].

With an estimated population of 23 million people [9], Ghana is still lacking safe drinking water in many communities. According to the Joint Monitoring Program for Water Supply and Sanitation of UNICEF and WHO, only 19\% of the Ghanaian rural populations have access to improved water resources [10]. Given the prevalence of diarrheal disease in Ghana, it is questionable whether even these water sources are potable. The paucity of access to safe drinking water has been shown to have detrimental effects on quality of life, health, social well-being and economic productivity $[11,12]$. These issues can become major obstacles to the sustainable development of impoverished countries. Specifically, diarrheal disease is associated with 670/100,000 disability-adjusted life years (DALYs) [6].

Although improved water sources have been established that allow increased access, studies in both urban [13-15] and rural [16, 17] settings have shown that the improved water source may still be contaminated. It has also been demonstrated that rural communities in Ghana use standing surface water sources such as ponds as a primary source or in addition to an improved source due to ease of access [16]. An earlier study of the three major rivers systems in Ghana that serve as the main source of drinking water for many rural villages documented that the rivers contained a high level of microbial pollution and were deemed unsafe to drink [18]. Due to the lack of infrastructure for mass water treatment, individual households require point-of-use treatment prior to consumption to decrease microbial pathogen load. The 2008 Demographic and Health survey (DHS) of Ghana reported that $90.3 \%$ of rural Ghanaians do not treat their drinking water [19]. Several recognized barriers exist relating to the treatment and include cost to treat, knowledge of proper treatment methods and access to necessary materials [20]. 
In rural communities, $19 \%$ of the population collected water from a source more than 30 minutes away [21], leading to the use of more contaminated water in the immediate vicinity. This water can then cross contaminate previously gathered water from other improved sources, leading to a false sense of water security. It has been found that the success of interventions aimed at improving drinking water quality depends on a variety of factors [22]. One major factor is seasonal availability often with severe water shortages in the dry season. Approximately $0.05 \%$ of the rural population depends on rainwater harvesting due to the unfavorable annual rainfall pattern in many parts of the country [23].

This paper describes a multidisciplinary team approach for the creation of a sustainable water infrastructure for an isolated agricultural community in the Kwahu South district, Ghana. The Kwahu South District is a heterogeneous community of Kwahus (66\%), Ashantis (17\%), Ewes (15\%) and other ethnic groups [24]. Oworobong is an agricultural community and site of the Heal the Home Health Clinic. This community relies on several sources of water: an improved water source in the form of two borehole wells (Kumi Well and Nsiah Well) and one surface water source, the Oworobong River, which is a major tributary draining into Lake Volta.

\section{Multidisciplinary team}

Students and faculty from the New York Institute of Technology (NYIT) Center for Global Health, the College of Osteopathic Medicine and the School of Engineering and Computing Sciences collaborated with the Jesse M. Rohde Foundation. This NGO is dedicated to providing preventative health strategies in this region of Ghana. The foundation is committed to positively affecting the lives of rural Ghanaians through public health (malaria nets, potable water pumps, sanitation/latrine construction), education (health outreach and scholarships for local students to become health care providers) and clinic services (prenatal monitoring programs and constructing sustainable clinics in rural communities). The foundation which has been working in Ghana for approximately 10 years has an established and respected reputation. The employees include Ghanaian nationals who live in or around the area of Oworobong. They are deeply committed to the projects and are a crucial component to its implementation as well as essential for cross cultural insight.

The goals of this project were three fold. First, health data was collected from the communities in and around Oworobong and evaluated for seasonable variability. Second, water was collected and analyzed for quality from several water sources used in Oworobong. Finally, an engineering solution was developed to reduce illness from water-borne pathogens.

\section{Methods}

\subsection{Chart review}

The chart review and methods were approved by the NYIT Institutional Review Board and reviewed by a consultant chosen by the Noguchi Memorial Institute 
for Medical Research, University of Ghana, Legon-Accra. The patient population came mostly from the following villages in the district: Awisesu, Chunwa, Deduekro, Miaso, Nteso, Odumase, Oframase, Ohema and Oworobong.

A chart review was conducted at the foundation's Heal the Home Clinic. Patient ID number, age, gender, home village, and diagnosis (as determined by staff nurses or visiting physicians) were recorded for all patients seen at the clinic from July, 2009 to July, 2010 (1479 patients) and January 2011 to July 2011 (1027 patients).

\subsection{Engineering/sanitation survey}

Engineering faculty and students from NYIT conducted a site visit in June 2010 to design a water infrastructure system using available sustainable resources and create a near-potable water quality resource for the clinic. Technical measurements using laser and Global Positioning System (GPS) were taken to create a digital layout of the site. The rainwater collection potential was determined based upon the average annual rainfall for the region. A rain gutter collection system and a storage and treatment system were designed. As the project developed special attention was given to the engineered solution to assure it would avoid creating potential mosquito breeding sites for malaria prevention.

A sanitation survey was also conducted around the community of Oworobong, examining sanitation and latrine availability and their relationship to community water sources. In order for water quality improvements to be effective, there must be an increased focus on sanitation. According to UNICEF $[25,26], 90 \%$ of rural Ghanaians use an unimproved sanitation facility, which does not ensure hygienic separation of human excreta from water and/or soil contamination. When sanitation conditions are poor, water quality improvements may have a minimal impact [27].

\subsection{Water testing}

Over a period of 12 months, from June 2010 to May 11, 2011, 72 water samples from a total of 18 experimental sites within the Oworobong community were investigated. Water samples were collected from the Oworobong River, borehole wells (Kumi and Nsiah) and household water containers. River samples were taken at a depth of $30 \mathrm{~cm}$ below the water surface with a sterile collection kit. Well water samples were collected by pumping water from the well and capturing a sample of mid-stream flow. After collection, the water was analyzed for total coliforms and fecal coliform. The results of the microbiological water quality testing were summarized in a report [28].

\section{Results}

\subsection{Chart review}

Of the 2506 charts reviewed, $391(15.6 \%)$ presented to the clinic with water related illness as a primary or secondary diagnosis (diarrhea, abdominal pain, 
etc.) over a period of 20 months. The younger patients (ages 0-19) were more likely to have water related illness compared to the older patients (ages 20-101); $\mathrm{OR}=1.4,95 \% \mathrm{CI}=(1.1,1.7)$ and the female patients were almost equally likely to have water related illness compared to the male patients; $\mathrm{OR}=0.9,95 \% \mathrm{CI}=$ $(0.7,1.1)$. On the other hand, $1035(41.3 \%)$ patients presented to the clinic with malaria over the same period of time. The younger patients (ages 0-19) were more likely to have malaria compared to the older patients (ages 20-101); OR = $3.8,95 \% \mathrm{CI}=(3.2,4.5)$, and the female patients were less likely to have malaria compared to the male patients; $\mathrm{OR}=0.8,95 \% \mathrm{CI}=(0.7,0.9)$.

Further statistical analysis was performed to test if the numbers of presentations for water borne illness and malaria were associated with the seasons as defined to be wet or dry by national precipitation data (April to July and September to November as wet season and December to March and August as dry season). Based on the results of statistical analysis stratified by age and gender, there was a trend that, among the younger patients (ages 0-19), more patients presented with water related illness during the wet season $(19.7 \%)$ when compared to the dry season $(16.0 \%)$; p-value $=0.09$. Among the older patients (ages 20-101), however, almost equal proportion of patients presented with water related illness during the wet season (13.4\%) and dry season (14.5\%); p-value $=0.29$.

With regard to malaria cases, there was a significant difference in the proportion of patients presented with malaria between the wet season $(39.0 \%)$ and the dry season $(45.4 \%)$, p-value $=0.002, \mathrm{OR}=1.3,95 \% \mathrm{CI}=(1.1,1.5)$. Based on the computed value of odds ratio, the risk of malaria was 1.3 times higher in the dry season than that in the wet season. When stratified by age and gender, the difference remains significant in the group of older female patients, but not in the other groups that are both the younger and older male patients and younger female patients. A lower proportion of patients among the older female patients (female of ages 20-101) presented with malaria during the wet season $(24.8 \%)$ when compared to the dry season $(33.7 \%), p$-value $=0.003, \mathrm{OR}=1.5$, $95 \% \mathrm{CI}=(1.2,2.0)$.

\subsection{Water testing}

Total number of coliforms and fecal coliforms were determined by fermentation tests according to the WHO standard [29-31]. Specifically, the total mean probable number $(\mathrm{MPN} / 100 \mathrm{ml})$ of coliforms with MacConkey broth after $48 \mathrm{~h}$ incubation at $37^{\circ} \mathrm{C}$ and the number (MPN/100 ml) of fecal coliforms with MacConkey medium after $24 \mathrm{~h}$ incubation at $44^{\circ} \mathrm{C}$ were the definitive measure of microbial contamination in all water systems. Positive results for both coliforms were confirmed on MacConkey agar (Sigma, USA). Colonies of each type were assessed by Gram-stains and confirmed by standard microbiological and biochemical procedures $[32,33]$. Parasites staining after concentration, by wet mount preparations were completed with GIEMSA and Zeihl Nielson stains. Microbiologic quality of Oworobong River, Kumi Well, Nsiah Well and random household water samples fetched from the Oworobong River or Kumi and Nsiah 
Wells were compared to WHO standard guidelines [34-36] for drinking water and the European commission guidelines for bathing water [37].

The Oworobong microbiological water study by Ayeh-Kumi [28] produced several important results. First, water from the Oworobong River and from household water containers was microbiologically contaminated. Fecal coliform levels exceeded both the WHO standards for drinking water and the European Commission guidelines for bathing water. Fecal contamination from both sources was highest during the June/August rainy season. This strongly suggests a cross-contamination from river water to home water containers and that local residents were repeatedly exposed to fecal coliform using river water as drinking water. This is also a time of water abundance and availability. A rain collection system from a roof dwelling could provide both convenience and a cleaner source when the river water is most contaminated.

Second, the borehole wells initially tested positive for fecal coliform but after treatment with chlorine, the wells consistently tested as bacteria-free. This made the wells the preferred choice as a drinking water source. However, the report also showed the ease with which clean water could be contaminated by collecting well water with containers also used to collect river water. It highlights the need to carry-out periodic testing of the wells to assure the water remains safe in addition to a behavioral intervention to prevent cross contamination.

\subsection{Sanitary survey of Oworobong}

A sanitary survey was conducted of Oworobong which contains approximately 500 residents. The survey found that the two borehole wells (Kumi and Nsiah) were vulnerable to contamination from numerous sources. The wells themselves were protected by a small concrete pad, approximately 6 feet by 6 feet. The area around the wells was often bare ground that received a high degree of foot traffic. Children frequently played around and on the well hand-pumps. The task of pumping water into home containers and carrying the open containers of water back home was mainly given to children. Dogs and other domesticated animals freely roamed around the well sites. There were no barriers around the wells to separate them from the local animals or residents not seeking well water.

There is one concrete community latrine located up-gradient of the Nsiah borehole well on the south side of the river. No treatment or disinfection was provided for the sanitary waste at the latrine. There were no facilities for villagers to wash their hands after using the latrine and throwing used toilet paper into the latrine was discouraged. Instead it was tossed into cans inside the latrine where it was later collected and burned. There were other more primitive latrine facilities scattered around the village, including several behind the health clinic in close proximity to the river. The public latrine is also some distance from the villagers living on the northern side of the river, making it more likely that those villagers are using hand-dug privies, the local terrain or the river for their sanitary needs.

Rainwater flows around the wells sites and into ditches that drain to the river. This allows any human or animal waste on the ground to be carried to the well 
sites and also into the river. Wild and domesticated animals freely wade into the shallow river contaminating it with animal excreta. The Oworobong river itself is used to wash clothes, for bathing, recreation, irrigation for food crops, for drinking water and for fish farming both upstream and downstream by the villagers.

The Oworobong Water Study [28] found that total coliform levels were higher in the upstream samples of the river water and carried into the village where residents could be exposed. However, fecal coliform levels were greater in the downstream river water, suggesting that this contamination was being generated by runoff from the village itself.

\section{Discussion}

The villagers of Oworobong use the water resources that are most convenient, either the traditional river water source or the two borehole wells. The 2011 Oworobong water quality study and other studies of similar water sources in Ghana indicate that the river water sources are rich in fecal bacteria and other water-borne pathogens. Kumasi et al. [34] studied the Barekese reservoir in Ghana and the nine streams draining into the reservoir which serves the city of Kumasi with a population of 2.5 million people. The study found that the nine streams were all contaminated with $E$. coli, and fecal coliform. In a broader study funded by the Bill and Melinda Gates Foundation, on diarrheal disease in infants and young children in communities from Africa and Asia, Kotloff et al. [38] found that there was a common pattern of illness due to four water-borne pathogens: rotavirus, Cryptosporidium, Escherichia coli, and Shigella. The study recommends aggressive intervention targeting these four pathogens to decrease diarrheal illness in the children by eliminating exposure to them. It also found that one of the controlling factors related to the degree of illness present was whether or not the children had access to improved water source.

Water conditions in Oworobong are typical of regions not sufficiently served by improved water sources. The challenge thus becomes how to provide a higher quality water source to a community without electricity or other modern infrastructure in an effort to protect the community from diarrheal illness.

\subsection{Rain harvesting project}

The Oworobong village experiences a double high rainfall seasonality which is referred to as the major and minor rainy seasons. The major rainy season runs from April through July. The minor rainy season runs from September through October. The average rainfall ranges between $1,580 \mathrm{~mm}$ and $1,780 \mathrm{~mm}$ (62 to 70 inches) according to The Oworobong Water Study [28]. Therefore, for approximately 6 months a year, the community has an abundant supply of rainfall that could be harvested for use as an alternative to the contaminated river. The rainwater can also be stored to extend the availability of safe drinking water into the dry season.

The Heal the Home Health Clinic is a large, south-facing rectangular building made of concrete with a large metal roof. The roof is divided into a south side 
and north side. The dimensions were measured. Based on the area of the roof and the frequency of rainfall, it was calculated that the roof could easily collect a significant amount of rainwater.

The combined front and rear roof area is 3,122 square feet. For a $1 / 4$ inch rainstorm, the roof could generate 486 gallons (1,840 liters) of water. For a $1 / 2$ inch rainstorm, the roof could generate 970 gallons (3,671 liters) and for a 1-inch rain storm, the roof could generate 1,947 gallons (7,370 liters) of water. For a year's worth of rain of 62 inches, the potential water available could exceed 120,000 gallons (454,200 liters). The project determined that rain harvesting from the metal roof was a viable alternative source of high quality water.

Several challenges were considered in the system design. They were:

1. Can the system be completely passive?

2. Can the system protect against the most common water-borne pathogens related to diarrheal illness (rotavirus, E. coli, Cyptosporidium, and Shigella)?

3. Can the system be designed to prevent potential malaria breeding sites in the community?

4. Can the system be simple and eliminate costly maintenance and upkeep?

Modern water systems are pressurized which allows for a variety of water treatment options. The Oworobong system would passively collect the water but it would require a power source to operate a disinfection system. The disinfection system selected was an ozone generation system powered by a solar energy panel that would be mounted on part of the south-facing roof. The ozone is effective on the four pathogens of concern, especially Cyptosporidium, which is resistant to other disinfection technologies. The ozone is regularly pumped into the tank and allowed to bubble through the water as a disinfectant. The ozone will also inhibit algae from developing on the tank interior.

Rainwater would be collected by a rain gutter system running around the front and rear roof sections and diverted into a large storage tank. A first-flush system would divert the first sludge of rainwater collected on the roof during a rainstorm so that is does not enter the storage tank. A series of filters of progressively finer mesh would also help to keep debris and some fine particles from entering the storage tank. The filters will be regularly cleaned. The tank would be covered to prevent debris and insects such as mosquitoes from gaining access to the water. This is particularly important for malaria prevention, and other water based disease, and special attention was paid to the size of the covering mesh. The tank can be periodically drained and cleaned of any material that may have settled to the bottom. The maximum tank size is roughly a 500 gallon tank. This size is the upper limit of what can be transported to the village in a small truck over unpaved roads. For more storage capacity, two tanks can be linked. This design is both low maintenance and low cost, and is durable enough to withstand environmental conditions found in the area.

\subsection{Future directions}

The clinic serves patients with many possible types of diseases. Therefore when considering the development of a safe water supply for the clinic, the collection of human wastewater must also be considered. Once a clean water supply is 
available, the community wastewater facilities must be upgraded and properly treated and disposed of to avoid further health risk to patients, local residents and clinic staff.

This project also investigated the likely locations for the development of a wastewater disposal system for the clinic. But in order to improve the purity of rivers like Oworobong, it is necessary to limit the inflow of contamination through runoff not only of a single structure but along the entire banks of the river. This requires the interventions on a larger scale with political activism and environmental legislation that unfortunately cannot be easily addressed at the local level. Interventions that can make a significant change include environmental education, proper chemical treatment of latrine waste and a change in agricultural practices. There is to date no legislation addressing water quality requirements, particularly the permitted number of microbes in surface water bodies. The National Water Policy of Ghana and Water Resources Commission (GWRC) is in the process of formulating policy documents for setting local standards to regulate the quality of water resources in Ghana [39].

The authors propose that the clinic can be an example to teach the community by demonstrating its importance through the establishment of a sustainable water infrastructure and propose a second phase of infrastructure development including wastewater management, sanitation control and education. The people of Oworobong have access to protected water (borehole wells) but some community members still have deep-seated preferences for water from streams and rivers. Unpublished data collected from a prior survey which investigated water usage in the area around Oworobong indicated that a water safety intervention for women and children would be the most appropriate. The clinic has the potential to set the example through its own use and health outreach.

\section{Conclusions}

While the initial goal of the project was to assess waterborne illness and provide a safe and reliable water supply for the clinic, it is expected that the clinic itself may stimulate community-wide economic development, creating further demand for similar infrastructure for the visiting public and for the residents themselves. Therefore water safety and health education will be available through community health workers and the clinic staff. Through this project we propose to model how educational institutions can bring their multidisciplinary expertise to underserved areas of the world and improve the quality of life in a sustainable manner.

\section{References}

[1] Boadi, K.O., Kuitunen, M., Environment, wealth, inequality and the burden of disease in the Accra metropolitan area, Ghana. International Journal of Environmental Health Research, 15(3), pp. 193-206, 2005. 
[2] Green, S. T., Small, M. J., Casman, E. A., Determinants of national diarrheal disease burden. Environmental Science \& Technology, 43(4), pp. 993-999, 2009.

[3] Prüss, A., Kay, D., Fewtrell, L., Bartram, J., Estimating the burden of disease from water, sanitation, and hygiene at a global level. Environmental Health Perspectives, 110(5), pp. 537-542. 2002.

[4] Whelan, J. J., Willis, K., Problems with provision: barriers to drinking water quality and public health in rural Tasmania, Australia, Rural and Remote Health, 2007. Online. http://www.rrh.org.au/articles/ subviewnew.asp?ArticleID=627 [Accessed 18 January 2010].

[5] Elimelech, M., The global challenge for adequate and safe water. Journal of Water Supply: Research and Technology, 55(1), pp. 3-10, 2006.

[6] The United Nations Children's Fund (UNICEF)/World Health Organization (WHO), Diarrhoea: Why children are still dying and what can be done, Online. 2009 http://whqlibdoc.who.int/publications/2009 /9789241598415_eng.pdf

[7] UNDP: International Human Development Indicators, Ghana: country profile of human development indicators, 2010. Online. http://hdrstats.undp.org/en/countries/profiles/GHA.html [Accessed 10 February 2011]

[8] Leclerc, H., Schwartzbrod, L., Dei-Cas., E. Microbial agents associated with waterborne diseases. Crit Rev Microbiol. 28(4):371-409. 2002

[9] World Health Organization (WHO), Ghana: data and statistics, 2009 Online. http://www.who.int/gho/countries/gha/data/en/index.html [Accessed 18 January 2010].

[10] WHO, Geneva and UNICEF, New York Joint Monitoring Programme. Progress on drinking water and sanitation: special focus on sanitation., World Health Organisation and United Nations Children's Fund Joint Monitoring Programme for Water Supply and Sanitation (JMP), pp. 1-15, 2008

[11] Elimelech, M. The global challenge for adequate and safe water. Journal of Water Supply: Research and Technology, 55(1), pp. 3-10. 2006.

[12] Buor, D. Water needs and women's health in the Kumasi metropolitan area, Ghana. Health and Place, 10, pp. 85-103, 2003.

[13] Kwakye-Nuako, G., Borketey, P., Mensah-Attipoe, I., Asmah, R., AyehKumi, P., Sachet Drinking Water in Accra: The Potential Threats of Transmission of Enteric Pathogenic Protozoan Organisms. Ghana Medical Journal. 41(2):62-7. 2007.

[14] McGarvey, S. T., Buszin, J., Reed, H., Smith, D. C., Rahman, Z., Andrzejewsky, C., Awusabo-Asare, K., White, M. J., Community and household determinants of water quality in coastal Ghana. Journal of Water and Health, 6(3), pp. 339-349, 2008.

[15] Reither, K., Ignatius, R., Weitzel, T., Seidu-Korkor, A., Anyidoho, L., Saad, E., Djie-Maletz, A., Ziniel, P., Amoo-Sakyi, F., Danikuu, F., Danour, S., Otchwemah, R. N., Schreier, E., Bienzle, U., Stark, K., Mockenhaupt, F. P., Acute childhood diarrhoea in northern Ghana: 
epidemiological, clinical and microbiological characteristics. BMC Infectious Diseases, 2007. Online. http://www.biomedcentral.com/content /pdf/1471-2334- 7-104.pdf [Accessed 15 December 2009].

[16] Anim, F., Nyame, F. K., Armah, T. K. Coliform status of water bodies from two districts in Ghana, West Africa: implications for rural water resources management. Water Policy, 12(5), pp. 734-745, 2010.

[17] Guillemin, F., Henry, P., Uwechue, N., Monjour, L. Faecal contamination of rural water supply in the Sahelian area. Water Research, 25(8), pp. 923927. 1991.

[18] Ampofo, J. A. A survey of microbial pollution of rural domestic water supply in Ghana. International Journal of Environmental Health Research, 7, pp. 121-130. 1997.

[19] Ghana Statistical Service (GSS), Ghana Health Service (GHS), ICF Macro, Ghana Demographic and Health Survey 2008. Accra, Ghana: GSS, GHS, and ICF Macro, 2009.

[20] Phaswana-Mafuya, N. An investigation into the perceived sanitation challenges in the Eastern Cape rural communities. Health SA Gesondheid, 11(1), pp. 18-30. 2005.

[21] World Health Organization (WHO). The global burden of disease: 2004 update. WHO, Geneva, pp. 11, 12, 14, 2008.

[22] Thompson, T., Sobsey, M., Bartram, J. Providing clean water, keeping water clean: an integrated approach. International Journal of Environmental Health Research. 13:S89-S94. 2003.

[23] World Bank. MDG Ghana Country Assessment, 2003 Online. http://www.undg.org/index.cfm?P=87 [Accessed 1/20/2010].

[24] World Health Organization (WHO), Ghana: data and statistics, 2009 Online. http://www.who.int/gho/countries/gha/data/en/index.html [Accessed 18 January 2010].

[25] UNICEF. At a glance: Ghana. 2010 Online. http://www.unicef.org /infobycountry/ghana_statistics.html [Accessed 15 December 2010].

[26] UNICEF, WHO. Progress on drinking water and sanitation: special focus on sanitation. UNICEF, New York and WHO, Geneva. pp. 13, 23, 2008 World Bank. MDG Ghana Country Assessment, 2003 Online. http://www.undg.org/index.cfm?P=87 Accessed 1/20/2010.

[27] Eisenberg, J., N., S. Integrating disease control strategies: balancing water sanitation and hygiene interventions to reduce diarrheal disease burden. American Journal of Public Health, 97(5), pp. 846-852, 2007.

[28] Ayeh-Kumi, P.F. Personal Communication November 2011, payehkumi@yahoo.com Department of Microbiology, University of Ghana Medical School, Accra, Ghana. Surveillance of Microbiological Quality of Water Resources for Consumption and Recreational Purposes in Oworobong, A rural community in the Kwahu East District, Ghana.

[29] World Health Organization (WHO). Guidelines for drinking water quality: Volume 1 Recommendations, 3rd edition. WHO Geneva, 2004. 
[30] World Health Organization (WHO) Guidelines for drinking water quality: Volume 111 Surveillance and control of community supplies, 2nd edition. WHO Geneva 1998.

[31] World Health Organization (WHO) Guidelines for drinking water quality: Volume 11 Health and other supporting criteria, 2nd edition. WHO Geneva 1996.

[32] Cowan, S.T., Steel, K. J. Characteristics of gram negative bacteria. Cowans and Steels Manual for identification of Medical bacteria. Barrow, G.I., Feltham, R.K.A., ed. Cambridge University Press. London. 94-150 1993.

[33] Cheesbrough, M. District Laboratory Practice in Tropical countries Part 2. In: Water related diseases and testing of water supply Cambridge University Press. London, 2006; 146-157.

[34] Kumasi, T.C., Obiri-Danso, K., Ephraim, J.H. Microbial quality of water in Barekese reservoir and feeder streams in Ghana. Lakes \& Reservoirs: Research and Management, 16: 49-60 2011.

[35] African Economic Outlook. Ghana country note 2007. p. 294. Online http://www.oecd.org/dataoecd/26/51/38562673.pdf Accessed 25 November 2010.

[36] Rossiter H.M.A., Owusu, P.A., Awuah, E., MacDonald, A.M., Schäfer, A.I. Chemical drinking water quality in Ghana: water costs and scope for advanced treatment. Sci. Total Environ., 408: 2378-86. 2010.

[37] European Economic Community: Council Directive of 8 December 1975 Concerning the Quality of Bathing Water, 76/160/EEC. Official Journal of the European Communities, C31, 1-7, 1976.

[38] Kotloff, K.L., Nataro, J.P., Blackwelder, W.C., Nasrin, D., Farag, T.H., Panchalingam, S., Wu, Y., Sow, S.O., Sur, D., Breiman, R.F., Faruque, A.S., Zaidi, A.K., Saha, D., Alonso, P.L., Tamboura, B., Sanogo, D., Onwuchekwa, U., Manna, B., Ramamurthy, T., Kanungo, S., Ochieng, J.B., Omore, R., Oundo, J.O., Hossain, A., Das, S.K., Ahmed, S., Qureshi, S., Quadri, F., Adegbola, R.A., Antonio, M., Hossain, M.J., Akinsola, A., Mandomando, I., Nhampossa, T., Acácio, S., Biswas, K., O’Reilly, C.E., Mintz, E.D., Berkeley, L.Y., Muhsen, K., Sommerfelt, H., RobinsBrowne, R.M., Levine, M.M. Burden and aetiology of diarrhoeal disease in infants and young children in developing countries (the Global Enteric Multicenter Study, GEMS): a prospective, case-control study. Lancet. pii: S0140-6736(13)60844-2. doi: 10.1016/S0140-6736(13)60844-2, 2013 May 13 [Epub ahead of print].

[39] Water Resources Commission (WRC), Annual Report, Water Resources Commission of Ghana, Online, 2011 http://doc.wrcgh.org/pdf/WRC\%20Annual\%20Report\%202011.pdf 